DOI 10.37882/2500-3682.2020.06.04

\title{
НЕЙРОПСИХОАНАЛИЗ - НОВЫЙ ВЗГЛЯД НА ПРИРОДУ ЧЕЛОВЕКА ИЛИ ПОДМЕНА СМЫСЛОВЫХ ПЛАТФОРМ?
}

\section{NEUROPSYCHOANALYSIS - A NEW LOOK AT HUMAN NATURE OR A SUBSTITUTION OF MEANINGS?}

\section{Danilkina}

Summary: The article analyzes the methodological possibilities of pairing an extremely important area of modern interdisciplinary knowledge - neurobiology. on the one hand, and the preservation of important positions in the field of psychology of psychoanalysis, on the other. The correctness of the application of the dynamic localization method proposed by the Soviet scientist A.R. Luria, to the ideas of psychoanalysis.

Keywords: neuropsychoanalysis, neurobiology, psychoanalysis, consciousness, behavior, interdisciplinarity.

\author{
Данилкина Дарья Сергеевна \\ Аспирант, Московский государственный \\ университет им. М.В. Ломоносова \\ darjadanilkina@rambler.ru
}

Аннотация: В статье проводится анализ методологических возможностей сопряжения чрезвычайно актуальной области современного междисциплинарного знания - нейробиологии. с одной стороны, и сохраняющего важные позиции в сфере психологии психоанализа, с другой стороны. Рассматривается корректность применения метода, динамической локализации, предложенного советским ученым А.Р. Лурия, к идеям психоанализа.

Ключевые слова: нейропсихоанализ, нейробиология, психоанализ, сознание, поведение, междисциплинарность.

\section{Введение}

Идея о локализации психических функций положила начало развитию современной науки - нейропсихологии.

Фрейд отвергал идею своих современников Брока и Вернике, о локализации психических функций в определенных сегментах головного мозга. Фрейд предполагал, что психические функции носят непрерывный и всеобъемлющий характер, более того, психические свойства не исчезают при локальных повреждениях мозга. Фрейд являлся сторонником идеи об умеренной локализации, он полагал, что функциональные состояния мозга определяют психологические свойства, а он состоит из определенных динамичных центров, и функции не определяются в мозге локально.

Сторонники теории нейропсихоанализа утверждают, что критика Фрейдом теории о локализации имеет решающее значение, так как это позволяет объединить психоанализ с нейробиологией. Действительно, стоит сказать, что критика идеи об узком локализиционизме Фрейда оправдана, современные исследования в области нейробиологии это доказывают. Впоследствии, появились возможности исследовать мозговую активность при помощи электроэнцефалограммы, метода вызванных потенциалов, а также МРТ и фМРТ, которые позволили регистрировать различные физиологические процессы, такие как память, внимание и т.д.

Сторонники нейропсихоанализа исходят из того, что, во-первых, считают методы Лурия, в контексте «мозгповедение», полностью идентичны методам, предложенным 3. Фрейдом. Фрейд являлся сторонником идеи об умеренной локализации речи, а Лурия считал, что все компоненты речи должны быть локализованы. Отвечая на вопрос: «почему Фрейд не смог вывести подобных заключений из своей клинической практики?», нейропсихоаналитики говорят о сложности теории языка, на которой основывались исследования Лурия, а так же о том, что в отличие от Фрейда, Лурии удалось создать методологический подход. Данные аргументы не являются вполне обоснованными, Фрейд и Лурия, ставили перед собой одну задачу, которая заключалась в стремлении показать, что нарушения ВПФ не является необратимыми, их восстановление возможно. Но методы, которые ими были разработаны, существенно отличаются, некорректно говорить, что Лурия в отличии от Фрейда подошел к данной проблеме методологически. Фрейдом тоже был предложен метод, но только который не смог в полной мере объяснить структуру психических качеств.

В работе «Бессознательное» Фрейд пишет о том, что психическая деятельность связана с функциями мозга, но идея приписать психические функции определенным участкам мозга не имеет основания, даже в силу неточности поставленной задачи. Идея представить мысли как скопления в нейронах, а возбуждение - процесс, проходящих по нервным волокнам - окончилась неудачей. Этот большой пробел наука заполнить пока не в состоянии. [Фрейд, 1998, с 161] Исходя из этого, Фрейд приходит к выводу, что изначально более рационально изучать психические процессы с позиций психологии, 
чтобы объяснить внутреннюю структуру психики, а затем уже подходить к определению корковой структуры этих процессов. По мысли сторонников нейропсихоанализа, такое заключение Фрейда дает право согласовать психоанализ с нейронауками, посредством «метода динамической локализации», предложенный А.Р. Лурия, который, по их убеждению, сможет воссоединить психоанализ с нейронаукой. А.Р. Лурия состоял в Москве Русском психоаналитическом обществе, проводил исследовательскую и клиническую работу в области психоанализа. Многие ученые считают, что история психоанализа в Советском Союзе началась с деятельности А.Р. Лурия. Но в 30-х годах ученому пришлось покинуть Русское психоналитическое общества и прекратить психоаналитическую деятельность, аргументируя такой поступок разочарованием в психоанализе, как науке, которая, как оказалось, не способна решить проблему различия между номотетическими и идеографическими подходами. Причиной отказа от психоаналитических идей также послужил факт исключения психоанализом из поля своего исследования - социальной природы человека, что, в свою очередь, по убеждению А.Р. Лурии, является большой ошибкой. Но сторонники нейропсихоанализа уверены, что отречение А.Р. Лурия от психоанализа было совершено из-за политического давления, и сам Лурия остался верен своим убеждениям.

Сразу хочу отметить, что принцип динамической локализации высших психических функций был сформулирован И.П. Павловым, а после нашел свое развитие в трудах А.Р. Лурия. Смысл данного учения заключается в том, что высшие психические функции осуществляются системами зон коры головного мозга, которые являются функционально высокодифференцированными. Т.е. если изменяется структура с развитием функции, то меняется и ее локализация (например, если происходит поражение зоны головного мозга, то меняется и локализация функции). Лурия предложил системный подход анализа ВПФ, который включает в себя стадию квалификации симптома и его анализ. Т.е. нужно искать, а не описывать фактор, который является причиной нарушения ВПФ, и прежде чем квалифицировать симптом, нужно изучить его структуру. Анализ симптома предполагает определение нарушения других функциональных систем, в результате поражения единичного участка мозга.

В ходе работы «Толкование сновидений» Фрейдом были выдвинуты 4 постулата:

1. Психические процессы носят бессознательный характер.

2. В психической жизни отсутствует понятие «случайность».

3. Бессвязные мысли не представляют собой отклонение от нормы.

4. Психика существует как непрерывный процесс.
Предложенная Фрейдом теория психики, состоит из трех ключевых структур: Я, Сверх-Я, Оно. Я представляет орган психики, включающий как сознательные, так и бессознательные компоненты. Сверх-Я объясняется как бессознательный компонент психики, отвечающий за моральные ценности. Компонент Оно по своей природе является бессознательным и представляет собой комплекс инстинктивных влечений, половых и агрессивных.

Нейропсихоаналитики называют бессознательное истинным объектом исследования научной глубинной психологии. Не нужно забывать тот факт, что Фрейд убрал свою теорию о бессознательном из ранга естественных наук, тем самым сведя на нет возможность связать эту модель с достижениями современной нейробиологии.

Лурия выделяет три функциональные блока мозга, которые необходимы для осуществления психической деятельности. Первый блок представляет собой аппарат регуляции тонуса и бодрствования, он обеспечивает полноценную работу речевого аппарата в состоянии бодрствования, т.к. именно таком условии, человек способен осуществлять полноправный контроль над своей психической деятельностью. Так же стоить отметить, что данный блок не отвечает за прием и переработку информации извне. В середине 20 века, Моруцци и Мэгун было обнаружено образование - ретикулярная формация, которое способно изменять тонус мозговой коры и приводить ее в состояние бодрствования. Второй блок отвечает за переработку и хранение информации. Теменная область отвечает за ориентацию в пространстве и обеспечивает кожную чувствительность, так же теменная область включает в себя центры праксиса, под которым понимают сознательные произвольные действия, которые формируются в процессе обучения. Затылочная область обеспечивает переработку зрительной информации, височная - слуховой. И третий блок отвечает за регуляцию и контроль сложных форм деятельности, он регулирует поведение в соответствии с поставленными целями и задачами, но эта регуляция осуществляется только при условии участия речи. [Лурия, 2003, с 88-126]

Нейропсихоаналитики пытаются «вписать» в эту вышеназванную концепцию психоаналитическую теорию Фрейда, с целью показать объективность гипотез Фрейда.

Блок регуляции тонуса и бодрствования, психоаналитики называют аналогом психической инстанции, которая в психоанализе описывается как Оно. Источниками эндогенной активации являются внутренние циклы нейрональных групп, химические процессы организма и внешний мир. Последний тесно связан с понятием внимания, формирующего определенные шаблоны поведения, которые закладываются прошлым опытом и, по 
своей природе, являются врожденными и тесно связанными с памятью. [Каплан-Солмз, 2016, с 232-233]

Модифицируют эти процессы, так называемые, метаболические и гуморальные регуляции в организме. Далее, если отсутствует внешний объект, который составляет внутреннюю потребность, то включаются механизмы памяти, что направляет сознание на потребность. Т.е. получается, что источники активации взаимодействуют друг с другом. [Каплан-Солмз, 2016, с 234-236]

Эти данные многие нейропсихоаналитики используют для того, чтобы подтвердить фрейдовскую теорию структурных отношений личности, выводя на один уровень понятие «активизирующая система» и «резервуар либидо» - скопление инстинктов и сексуальных влечений. В этой связи снова возникают вопросы: не имеем ли мы опять дело с подменой смысловых платформ? Хотя корректнее было бы поставить вопрос следующим образом: что все-таки проясняет такой синтез?

Приступая к анализу функционального блока, который отвечает за регуляцию и контроль деятельности, нейропсихоаналитики констатируют, что им снова с поразительной легкостью удалось найти анатомические связи с метапсихологическими работами Фрейда. [Каплан-Солмз, 2016, с 236] Процессы, которые порождает этот функциональный блок, по утверждению сторонников нейропсихоанализа, имеют отношения к структурированию Сверх-Я. [Каплан-Солмз, 2016, с 241]

Это объясняется тем, что речь ребенка совершенствуется, когда он слушает голос родителей и пытается подстроиться под него, корригируя свое поведение, у него развивается способность критически его оценивать. Таким образом, Сверх-Я формирует барьер, который защищает Я от влечений и требований.

Интересным в это связи является факт, что у людей с шизофренией и аутизмом эта система функционирует слабо. Все вышеперечисленное еще раз говорит о том, что в ходе экспериментальной проверки, некоторые идеи А.Р. Лурия подтвердились. Возможно, такое внедрение психоаналитического учения Фрейда о Сверх-Я в вышеизложенную концепцию, представляется спорным. Действительно, Сверх-Я, в теории Фрейда, представляет собой комплекс моральных ограничений. Формирование Сверх-Я связано с преодолением Эдипова комплекса, существование которого, вызывает большие сомнения. Сверх-Я, в теории Фрейда, формируется следующим образом: «идеалу Я» пришлось трудиться над вытеснением Эдипова комплекса, более того, что само оно и возникло даже в результате этого перелома... Чем сильнее был Эдипов комплекс, тем быстрее (под влиянием авторитета, религиозного учения, обучения и чтения) произошло его вытеснение, тем строже
«Сверх-Я» будет позже царить над «Я» как совесть, может быть, как бессознательное чувство вины». [Фрейд, 1991, с 370] Нейропсихоаналитики несправедливо «опустили» психоаналитическую трактовку формирования Сверх-Я, которую даже с большой натяжкой тяжело внедрить в модель Лурии. Сторонники нейропсихоанализа, основываясь на методе динамической локализации А.Р. Лурия, который, по их мнению, способен воссоединить психоанализ и нейробиологию, предлагают показать его эффективность в контексте последних исследований в области сновидений. Основываясь на данных компьютерной томографии, удалось выяснить, что сновидения нарушаются при повреждении шести различных зон головного мозга. При повреждении в нижней теменной области - сновидение не осознается. Повреждение в левой нижней теменной доли проявляется в неспособности строить абстракции. [Каплан-Солмз, 2016, с 48-50]

Далее, следуя методу Лурии, можно заключить, что нарушение сновидения укладывается в этот синдром и такие понятия как абстракция, осмысление и символизация, являются функциональными компонентами процесса сновидения. Повреждение правой нижней теменной доли связано с фактором, который определяется нарушением способности удерживать зрительно-пространственную информацию в сознании, [Каплан-Солмз, 2016, с 50-51] из этого можно заключить, что данная функция так же является неотъемлемой составляющей сновидения.

Билатеральные повреждения белого вещества головного мозга, сопровождаются адинамией. Фундаментальной нарушенной функцией в данном случае является спонтанная мотивация. [Каплан-Солмз, 2016, с 51-52]

В отечественной психиатрии под термином «адинамия» подразумевается не снижение мотивационного побуждения, а значительный упадок сил и мышечную слабость. Возможно, здесь имеется ввиду понятие «аспонтанность», которая характеризуется невозможностью самостоятельного включения больного в выполнение какой-либо деятельности, когда на просьбу показать какое-либо движение - реакции не поступает. [Визель, 2005]

Нейропсихоаналитики уверены, что такого рода данные, подтверждают точку зрения Фрейда о том, что сновидения не носят отрывочный характер, а поддаются толкованию. Можно согласиться с тем, что сновидения психологичны, но вопрос о возможности их толкования, остается открытым. Толковать сновидения, в рамках модели психоанализа, значит методом свободных ассоциаций выявлять подавленные желания, толковать символы, но которые, как правило, предполагают сексуальный контекст, что еще раз говорит о пробелах в попытке интеграции двух дисциплин. 
Можно согласиться с израильскими учеными Бласс и Кармели, которые, находясь в оппозиции к нейропсихоанализу, говорят о том, что регистрация уровня активности мозга во время сновидения, ничего не добавляет к психоаналитической теории желаний. [The British Journal of Psychiatry, 2013]

Более того, нейронаука ставит под сомнение осмысленность таких процессов, поэтому описание нейронных коррелятов, лежащих в основе сновидения, не дает содержательных данных.

В отличии от Фрейда, К. Юнгом был выстроен более целостный подход к понимаю сновидений. Отказавшись от метода свободных ассоциаций, и используя метод ассоциаций, который способен возвращать сновидца к анализу первоначального образа в сновидении. Юнг считал, что исключительно в базовых сюжетах сновидения и заключается весь смысл. По Юнгу, нужно отличать сновидения, которые порождены повседневным опытом сновидца от сновидений, которые были рождены в глубинах коллективного бессознательного. Поэтому, чтобы уметь правильно искать смысл сновидения, нужно обладать глубокими знаниями в области мифологии и философии. Важно подчеркнуть, что согласно теории Юнга, задачей сновидения в контексте психической жизни, является восстановление психического равновесия. Анализировать «правильность» предложенного Юнгом подхода к анализу сновидения - задача отдельного исследования. Но метод поиска мифологических параллелей, скорее объясняется большим интересом Юнга к изучению мифологии, и сомнительность предложенной методики поиска универсального языка нашего подсознания, до сих пор вызывает много споров. Поэтому, психоаналитическое понимание толкования сновидений не совсем укладывается в рамки нейропсихологического подхода, предложенного А.Р. Лурия, как считают большинство нейропсихоаналитиков.

Действительно существуют случаи, когда пациенты перестают в сновидениях видеть мысленные образы, это происходит при повреждении височно-базальных областей коры головного мозга и расстройство сопровождается симптомом, который называется visual irreminiscence или visial anoneria, буквально «невозможность представления».[Каплан-Солмз, 2016, с 52]

Данная патология характеризуется визуальной потерей образов сна, неспособностью вырабатывать ментальные образы как в сновидении, так и в состоянии бодрствования.

В отечественной литературе, объяснения такому понятию нет. Нейропсихоаналитики, проводя параллель с теорией Фрейда, отмечают, что вышеописанная ситуация, так же известная как зрительная активация образа, связана с фрейдовским понятием «визуальная репрезентация» и коррелирует со сновидением зрительно-галлюцинаторного содержания. А также констатируют, что процесс зрительной активации образа схож с механизмом топографической регрессии, которую предлагает Фрейд. [Каплан-Солмз, 2016, с 56]

Отсюда нейропсихоаналитики делают вывод о том, что абстрактному, символическому характеру сновидения, предшествует этап чувственного представления и, таким образом, процесс сновидения включает в себя галлюцинации. Действительно, Фрейд вводит понятие регрессии, под которой понимает важную черту процесса сновидения, имеющей галлюцинаторный характер, а четкость зрительных восприятий обуславливается их перцептивной природой, а галлюцинации представляют собой мысли, которые превратились в перцептивные образы.

Как мы видим, здесь снова наблюдается неудачная попытка вписать новые исследования в области нейробиологии в рамки психоанализа. Проблеме нарушения образного мышления, в контексте данной проблемы, тяжело приписать галлюцинаторный характер, исходя из принятых определений понятия «галлюцинация» в теории психоанализа.

Потеря способности различать реальность и сновидение наблюдается у пациентов с повреждением лобной лимбической области. Нейропсихоаналитики приписывают данному синдрому фактор - нарушение тестирования реальности, термин, почерпнутый из психоаналитического учения, который означает неумение разграничивать психические образы и внешние объекты. [Каплан-Солмз, 2016, с 53] Примечательным здесь является то, что данный фактор сторонники нейропсихоанализа соотносят с понятием дефицита психической избирательности, введённым А.Р. Лурия.

Действительно, в лекциях по общей психологии, Лурия приписывал мнестической деятельности (процесс специального запечатления и заучивания материала) избирательный характер, суть которого заключается в умении разграничить предложенный для запоминания материал от ассоциаций или впечатлений. В работах по нейропсихоанализу, в контексте исследований А.Р. Лурия, исследователи достроили понимание феномена: под дефицитом психической избирательности уже понимается неспособность различать восприятие, воспоминание, фантазию, сновидение и мышление. [Каплан-Солмз, 2016, с 67]

И последний симптом появляется при височнолобных приступах, когда пациент сталкивается с частыми кошмарами, которые связаны с эпилепсией и 
описаны как судорожные эквиваленты, из чего можно сделать вывод, что судорожная активность в лимбической области является катализатором такого рода сновидений, и отсюда можно заключить, что фактор эмоционального возбуждения играет одну из ключевых ролей процесса сновидения. [Каплан-Солмз, 2016, с 54-55]

Анализируя шесть симптомов, можно сделать вывод, что процесс сновидения работает по принципу функциональной системы, которая включает в себя шесть участков головного мозга, и функция сновидения не локализуется в пределах одной из областей, она представляет собой динамический процесс между этими областями, т.е. предложенный А.Р. Лурией метод динамической локализации, действительно, работает. Снова обращу внимание следующее обстоятельство: эти исследования были опубликованы Лурией уже не под влиянием психоанализа, но нейропсихоаналитики, как уже было указано выше, ссылаются на верность Лурии психоаналитическим традициям и утверждают, что метод, предложенный Лурия, полностью совместим с идеями Фрейда о неправомерности локализации психических функций в определенных областях мозга. Поэтому, утверждать, что данный факт свидетельствует о том, что базовые допущения Фрейда можно совместить с данными нейробиологии, на основании применимости на практике метода Лурии, нерационально. Эта идея задолго была сформулирована немецким физиологом Гольцем (1876-1881), в ходе экспериментов по удалению определенных участков коры больших полушарий у собак.

Он пришел к выводу, что после удаления отдельных участков, нарушение поведения проявлялось в реакции мозга как целого, далее функции и нарушения восстанавливались, из чего Гольц заключил, что «любая часть мозга имеет отношение к образованию воли, ощущений, представлений и мышления и что степень функциональной утраты стоит в прямой зависимости только от величины поражения». [Лурия, 1962, с 14]

\section{Зак^ючение}

Толкование сновидений, считает Фрейд, является королевской дорогой к изучению подсознательной деятельности мозга. Утверждение, что каждое сновидение является исполнением желания - обосновать невозможно. Но Фрейд в этом случае делает достаточно интересный ход: он устанавливает правила расшифровки снов. Таким образом, изменяя трактовки, он всегда приходил к нужному заключению, даже если внешнее содержание снов подразумевало иное.

Для Фрейда важным было то, что он имел возможность решать, как интерпретировать определенный символ в сновидении. Но, труда не согласиться, что такой метод может свести к абсурду любую науку.

Вышеизложенные положения позволяют сделать выводы о том, что идеи психоанализа лишь частично подтверждаются нейробиологическими исследованиями, интерпретация нейробиологических открытий в рамках теории Фрейда, на сегодняшний день, не лишена противоречий. Возможно, требуется иной теоретико-методологический подход, который будет содержать строгие аргументы. Ведь многие положения психоанализа, при всем разнообразии средств, имеющихся у современной науки, сегодня нельзя проверить.

Стоит особо подчеркнуть три важных идеи, которые были предложены Фрейдом, и впоследствии легли в основу современной нейробиологии:

1. психическая жизнь в значительной мере управляется бессознательными процессами, сознанию принадлежит малая часть психики;

2. инстинктивное поведение (агрессивное и половое) управляется психическими процессами в головном мозге и содержится в геноме на ранних стадиях. Эту идею Фрейда подтверждают исследования, проведенные Панскеппом в 20 веке

3. психические расстройства нельзя отделять от психической жизни, составляющей норму, первые являются крайней формой нормальных процессов психики.

1. Баарс Б., Гейдж Н. Мозг, познание, разум: введение в когнитивные нейронауки: в 2 ч. Т. 1. М.: Бином. Лаборатория знаний, 2014.

2. Баарс Б., Гейдж Н. Мозг, познание, разум: введение в когнитивные нейронауки: в 2 ч. Т. 2. М.: Бином. Лаборатория знаний, 2014.

3. Баландин Р.К. Тупики психоанализа. Роковая ошибка Фрейда. М.: Вече, 2014.

4. Дубровский Д.И. «Обман. Философско-психологический анализ». URL: http://www.globalistika.ru/dubrovsky/nauchnye_texty/obman4.htm (дата 0бращения: 12.02.2020).

5. Дубровский Д.И. Бессознательное (в его отношениях к сознательному) и квантовая механика. URL: http://novainfo.ru/article/780 (дата 0бращения: 03.03.2020).

6. Дубровский Д.И. Психика и мозг: результаты и перспективы исследования. URL: http://web-local.rudn.ru/web-local/uem/ido/psix_fiz/ch1_4.html (дата обращения: 02.02 .2020$)$. 
7. Каплан-Солмз К., Солмз М. Клинические исследования в нейропсихоанализе, введение в глубинную нейропсиологию. М.: Академический проект, 2016.

8. Конечный и бесконечный анализ Зигмунда Фрейда / Под ред. Д. Сандлера. М.: Канон + РООИ «Реабилитация», 2016.

9. Лурия А. Р. Основы нейропсихологии. Учеб. пособие для студ. высш. учеб. заведений. М.: Академия, 2003.

10. Лурия А.Р. Высшие корковые функции человека и их нарушения при локальных поражениях мозга. М.: Изд-во Московского Университета, 1962.

11. Риззолатти. Д., Коррадо С. Зеркала в мозге: 0 механизмах совместного действия и сопереживания. М.: Языки славянских культур, 2012.

12. Фрейд 3. «Я и Оно». Тбилиси: Мерани, 1991.

13. Фрейд 3. Введение в психоанализ. М.: АСТ, 2014.

14. Фрейд 3. Основные принципы психоанализа. М.: Рефл-бук, 1998.

15. Фрейд 3. Основные психологические теории в психоанализе. Очерк истории психоанализа. СПб.: Алетейя, 1998.

16. Фрейд 3. Толкование сновидений. М.: Азбука-классика, 2006.

17. Фрит К. Мозг и душа: как нервная деятельность формирует наш внутренний мир. М.: Астрель; CORPUS, 2010.

18. Фромм Э. Теория Фрейда: Миссия Зигмунда Фрейда. Анализ его личности и влияния. Величие и ограниченность теории Фрейда. М.: Астрель, 2012.

19. Hobson A. Freud Returns? Like a Bad Dream // American Scientific. Volume 17, 2006.

20. Justifying psychoanalysis // The British Journal of Psychiatry, 2013.

21. Ramus F. What's the point of neuropsychoanalysis? // The British Journal of Psychiatry, 2013.

○ Данилкина Дарья Сергеевна (darjadanilkina@rambler.ru).

Журнал «Современная наука: актуальные проблемы теории и практики»

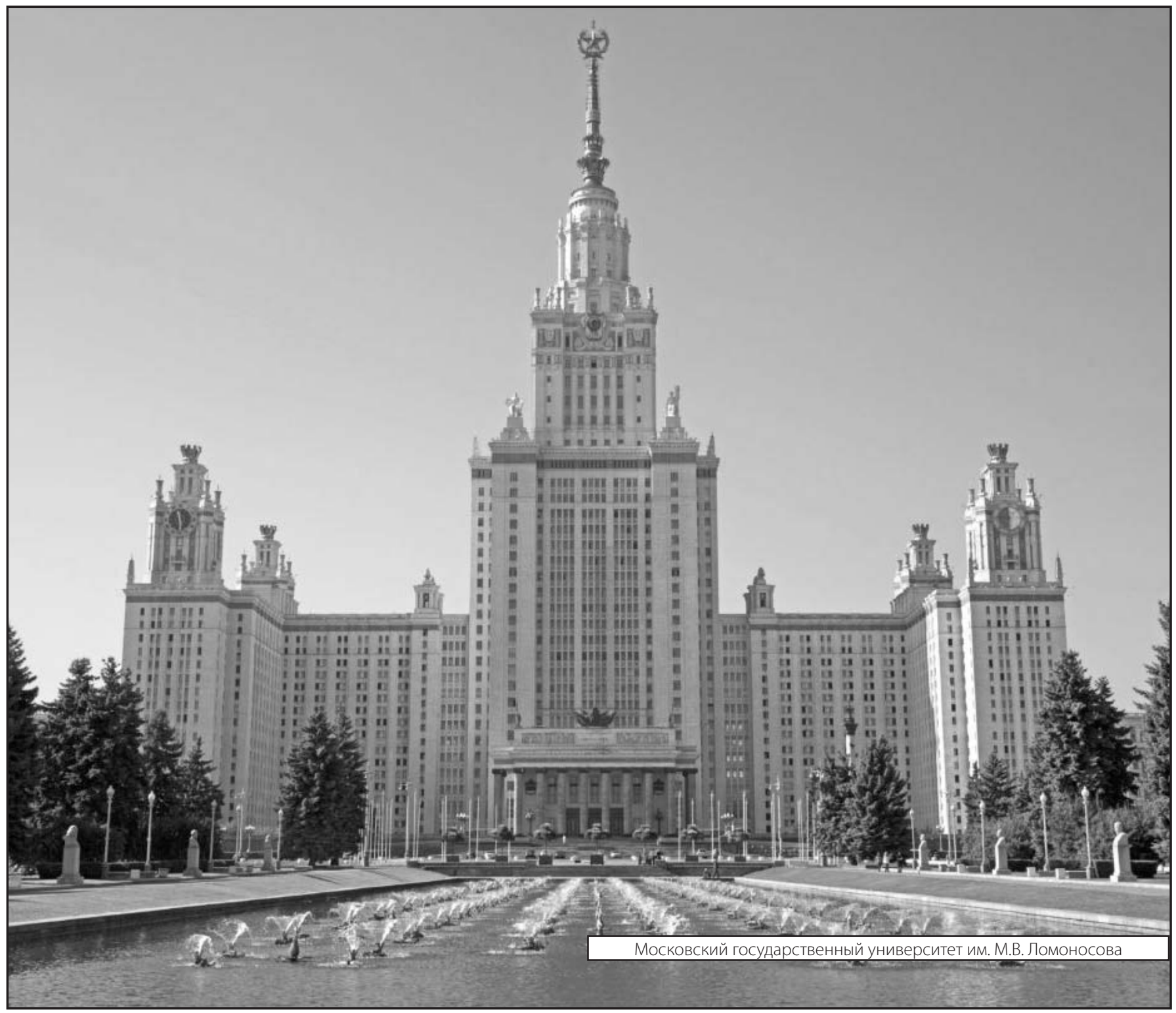

